\title{
Influence of Shared Medical Appointments on Patient Satisfaction: A Retrospective 3-Year Study
}

Leonie Heyworth, MD, MPH ${ }^{1,2}$

Ronen Rozenblum, PbD, MPH ${ }^{2}$

James F. Burgess, Jr, $P b D^{1}$

Errol Baker, $P b D^{1}$

Mark Meterko, $\mathrm{PbD}^{1}$

Debra Prescott ${ }^{3}$

Zeev Neuwirth, MD, $S M^{4}$

Steven R. Simon, $M D, M P H^{1,2}$

'Veterans Administration Boston Healthcare System, Jamaica Plain, Massachusetts

${ }^{2}$ Division of General Internal Medicine, Brigham and Women's Hospital, Boston, Massachusetts

${ }^{3}$ Harvard Vanguard Medical Associates, Newton, Massachusetts

${ }^{4}$ Carolinas Healthcare, Charlotte, North Carolina

Conflicts of interest: Ms Prescott has provided consulting services to Cambria Health.

\section{CORRESPONDING AUTHOR}

Leonie Heyworth, MD, MPH Section of General Internal Medicine VA Boston Healthcare System 150 S Huntington Ave, Mailstop 152G Jamaica Plain, MA 02130 lheyworth@gmail.com

\begin{abstract}
PURPOSE Shared medical appointments (SMAs) are becoming popular, but little is known about their association with patient experience in primary care. We performed an exploratory analysis examining overall satisfaction and patient-centered care experiences across key domains of the patient-centered medical home among patients attending SMAs vs usual care appointments.
\end{abstract}

METHODS We undertook a cross-sectional study using a mailed questionnaire measuring levels of patient satisfaction and other indicators of patient-centered care among 921 SMA and 921 usual care patients between 2008 and 2010. Propensity scores adjusted for potential case mix differences between the groups. Multivariate logistic regression assessed propensity-matched patients' ratings of care. Generalized estimating equations accounted for physician-level clustering.

RESULTS A total of $40 \%$ of SMA patients and $31 \%$ of usual care patients responded. In adjusted analyses, SMA patients were more likely to rate their overall satisfaction with care as "very good" when compared with usual care counterparts (odds ratio $=1.26 ; 95 \% \mathrm{Cl}, 1.05-1.52$ ). In the analysis of patientcentered medical home elements, SMA patients rated their care as more accessible and more sensitive to their needs, whereas usual care patients reported greater satisfaction with physician communication and time spent during their appointment.

CONCLUSIONS Overall, SMA patients appear more satisfied with their care relative to patients receiving usual care. SMAs may also improve access to care and deliver care that patients find to be sensitive to their needs. Further research should focus on enhancing patient-clinician communication within an SMA as this model of care becomes more widely adopted.

Ann Fam Med 2014;324-330. doi: 10.1370/afm.1660.

\section{INTRODUCTION}

S hared medical appointments (SMAs), or group visits, have demonstrated enhanced access and productivity in primary care. ${ }^{1}$ The Patient Protection and Affordable Care Act of 2010 has coincided with the emergence of patient-centered medical homes (PCMHs) that are embracing innovative methods of care delivery to increase the role of primary care. ${ }^{2}$ Organizations transforming their care delivery approach toward a medical home model seek strategies to accommodate increased numbers of patients projected to become insured under the Act. SMAs represent a potential innovation to improve access, cost, disease management outcomes, and patient-centered care. ${ }^{1,3-5}$

Patient-centered care and satisfaction are increasingly being recognized as essential components of health care quality, ${ }^{6}$ and large payers are recognizing patient-centered care as a core element of quality health care delivery and have started to link measures of patient satisfaction to reimbursement. ${ }^{7}$ As one of the pioneer Accountable Care Organizations, Harvard Vanguard Medical Associates, a large, multispecialty group practice in eastern Massachusetts, has implemented novel programs focused on disease management and patient experience. The SMA program was 
integrated practicewide by 2008 and is one of the most publicized examples of large-scale SMA implementation within primary care. ${ }^{8}$

On the basis of published studies, the SMA model has gained patient acceptance in subspecialty clinics $^{9-12}$ and chronic disease management. ${ }^{13-16}$ Additionally, SMAs have demonstrated decreased direct medical costs as well as improvements in guideline adherence and glycemic control in diabetes management. ${ }^{3,17}$ Smaller studies of patient satisfaction with SMA conducted among geriatric patients ${ }^{10,11,17}$ and those with diabetes ${ }^{18,19}$ have had mixed results.

There is little literature describing patient perceptions of SMA using the PCMH patient experience framework developed by the National Committee for Quality Assurance. ${ }^{18}$ Yet awareness of how innovative models of care, such as the SMA, perform against these metrics will become increasingly valuable as payers embrace the concept of "pay for experience." To explore the influence of SMAs on patient experience within primary care, particularly with respect to measures of patient-centered care, we undertook this 3 -year study comparing the experience of individuals attending SMA visits with those attending traditional (individual) primary care office visits in a large multispecialty group practice.

\section{METHODS}

\section{Study Design and Data Collection}

The study compared patients attending SMAs and those attending usual care visits. In both groups, we conducted cross-sectional surveys of patients' experiences with care. We administered by mail the medical experience questionnaire developed by Press Ganey (www.pressganey.com), a validated and reliable survey instrument widely used commercially to measure patients' experience with outpatient care. Questionnaires were mailed 1 week after a patient's encounter. Survey responses from 2008 to 2010 were analyzed retrospectively. A total of $40 \%$ of SMA patients and $31 \%$ of usual care patients completed the questionnaires. The Partners Healthcare Institutional Review Board approved the study protocol.

\section{Setting and Patients}

The study was conducted within Harvard Vanguard Medical Associates, a multispecialty group of 14 practices in Massachusetts with an established SMA program and existing patient experience reporting. ${ }^{19}$ Patients who had at least 1 internal medicine office visit from 2008 to 2010 were stratified by primary care clinician. For each clinician, questionnaires were mailed to 200 randomly selected patients, evenly distributed over the course of each of the 3 study years; each patient was surveyed only once per year. From January 2008 to December 2010, a total of 34,619 patients who received usual care and 981 patients who had selfselected to receive SMA care completed the questionnaire. SMA and usual care patients were propensity matched to adjust for possible case-mix differences (see Statistical Analysis section).

\section{Shared Medical Appointments}

Each 90-minute SMA comprised approximately 10 patient-participants and a care team consisting of a primary care internist, a behaviorist (eg, a psychologist, social worker, or nurse practitioner, whose role it was to facilitate discussion among the participants about positive health-related behavior change), and a documentation specialist. Patients were invited to participate in SMAs through mailed letters or when scheduling appointments. Additionally, each facility advertised SMAs through posters hung in waiting areas within internal medicine clinics. SMA participants generally attended SMAs led by their primary care physician. During SMAs, physicians attended to each patient sequentially, generally spending 5 to 10 minutes eliciting and discussing each patient's clinical problems with the group. The SMAs we examined were all within internal medicine, examples of SMA topics included diabetes and general issues, and SMAs dedicated to annual physical examinations.

\section{Main Outcome Measures}

The primary outcome was the single survey item response for overall visit satisfaction, "overall rating of care provided during your visit," rated on a 5-point Likert scale as "very good," "good," "fair," "poor," or "very poor." We dichotomized these ratings as "very good" vs other responses based on the negative skew (more than 10\% of the sample at the positive end of the distribution) of the variables examined. In addition, we identified 5 domains within the Press Ganey questionnaire that reflect the core principles of the $\mathrm{PCMH}^{20}$ : enhanced access to care (4 items), visit coordination and quality (4 items), physician communication (4 items), team-based care ( 2 items), and whole-person orientation of care (3 items). Each domain was measured on the same scale and similarly dichotomized as the primary outcome. We also examined rates of overall satisfaction with SMA across each year of the study, 2008 to 2010. Additionally, we stratified participants by the number of SMAs attended and compared levels of satisfaction.

Individual responses on the questionnaires were identified a priori as characteristics that may have played a role in patients' decisions to pursue SMA care. These variables were linked to the patient's medical 
record, providing demographic information (age, sex, race, insurance status), health care use (the number of internal medicine and urgent care visits in the 6 months preceding their surveyed visit), certain medical conditions (hypertension, diabetes, cardiovascular disease), body mass index, and primary care clinician characteristics (sex and years since hire). For the SMA group, we ascertained the number of previously attended SMAs. Cut points for continuous variables were chosen around the median values within the distribution of each of these variables.

\section{Statistical Analysis}

All variables used in the patient experience analysis are dichotomous. Our main analysis was to compare SMA and usual care groups with respect to patient experience. To minimize selection bias, descriptive statistics of patient characteristics and experiences in the SMA and usual care groups were calculated using a propensity score..$^{21}$ In general, propensity score methods permit control for observed confounding factors that might influence both the outcomes (in our study, patient experiences) and comparison groups (patients electing to receive SMA care vs those receiving usual care) using a single composite measure. The propensity score then attempts to balance patient characteristics between the comparison groups, as would occur in a randomized experiment. ${ }^{22}$

Patients were stratified into 2 strata comprising SMA and usual care. We computed propensity scores for each patient within each stratum. ${ }^{23}$ Propensity scores were obtained by regressing whether patients received SMA care on all patient characteristics available (details above). We matched each patient receiving SMA care with 1 patient receiving usual care whose logit of their propensity score was within \pm 0.0005 standard deviations of the logit of the SMA patient's score. Unmatched patients were excluded. All subsequent analyses included 921 patients who had experienced SMA care and 921 matched usual care patients.

We performed multivariate logistic regression to examine differences in overall satisfaction and other measures of patient-centered care among propensity score-matched SMA and usual care participants. In analyses restricted to SMA attendees, we used multivariate logistic regression analysis to evaluate differences in overall satisfaction stratified by the number of SMAs attended and also examined characteristics of the patients providing the highest ratings of care, incorporating all available covariates into the model. Generalized estimating equations ${ }^{24}$ were used to account for physician-level clustering. Trends in SMA satisfaction over time were ascertained using the Cochran-Mantel-Haenszel test. All analyses were com- pleted using SAS version 9.3 (SAS Institute); a $P$ value $\leq .05$ was considered statistically significant.

\section{RESULTS}

\section{Baseline Characteristics}

Baseline characteristics of the patients responding to the patient experience survey from 2008 to 2010 are shown in Table 1 . Before propensity matching, 981 had attended an SMA and 34,619 had had a usual care internal medicine visit. After propensity matching, there were no differences between the 921 SMA and 921 usual care matched patients. More than one-half of propensity-matched SMA and usual care patients were male $(57 \%$ and $55 \%$, respectively); a majority of patients self-identified as being of white race ( $91 \%$ and $89 \%$, respectively); similar proportions of SMA patients (51\%) and usual care patients (49\%) were aged 65 years or older. The propensity-matched SMA and usual care patients were similar with respect to all other variables examined (Table 1).

\section{Main Outcome Measures}

When compared with usual care peers, SMA patients were more likely to rate their satisfaction with care as "very good" (Table 2). In analyses that adjusted for clinician-level effects, overall satisfaction was better in the SMA group compared with the usual care group (adjusted odds ratio $[\mathrm{OR}]=1.26 ; 95 \% \mathrm{CI}, 1.05-1.52$ ).

SMA patients were more likely than usual care counterparts to rate their visit favorably in the access to care domain, most notably in their ability to access an appointment of their choice (adjusted OR $=1.49$; $95 \% \mathrm{CI}, 1.21-1.92)$. In this domain, SMA patients also rated the convenience of office hours more favorably than usual care peers (adjusted $\mathrm{OR}=1.22 ; 95 \% \mathrm{CI}$, 1.02-1.45) and reported a shorter wait for laboratory testing (adjusted $\mathrm{OR}=1.49 ; 95 \% \mathrm{CI}, 1.21-1.92$ ).

In contrast, when compared with usual care patients, SMA patients reported lower satisfaction across the personal physician communication domain, which focused on perceptions of the clinician's characteristics during the surveyed encounter. SMA patients provided a lower rating than usual care peers for clinician explanations (adjusted OR $=0.60 ; 95 \% \mathrm{CI}, 0.50$ 0.73 ), information given about medications (adjusted $\mathrm{OR}=0.64 ; 95 \% \mathrm{CI}, 0.54-0.77)$, concern expressed by clinician (adjusted $\mathrm{OR}=0.58 ; 95 \% \mathrm{CI}, 0.50-1.70$ ), and perceived time spent with the clinician (adjusted $\mathrm{OR}=0.52 ; 95 \% \mathrm{CI}, 0.50-1.60)$, with $P$ for all comparisons $<.001$ (Table 2).

In the orientation of care domain, SMA participants responded more favorably with respect to enhanced sensitivity to their needs at the surveyed visit (adjusted 
$\mathrm{OR}=1.34 ; 95 \% \mathrm{CI}, 1.08-1.65)$. Similar ratings were observed between SMA and usual care patients across the coordination of care and team-based care domains. We did not observe any differences between the groups' willingness to recommend their clinician (adjusted OR $=0.93 ; 95 \% \mathrm{CI}, 0.75-1.16$ ).

\section{Outcomes for SMA Patients Only}

In analyses restricted to SMA patients, we found that they were more likely to provide a higher rating of their care if they were of white race (adjusted $\mathrm{OR}=2.09 ; 95 \% \mathrm{CI}, 1.17-3.74)$ or attended 2 or more SMAs (adjusted OR $=1.51 ; 95 \% \mathrm{CI}, 1.06-2.12$ ).

Stratification by the number of SMAs attended (Table 3) demonstrated that the 569 patients attending 2 or more SMAs reported higher ratings of overall satisfaction with their care compared with patients attending $1 \mathrm{SMA}$ (adjusted $\mathrm{OR}=1.86 ; 95 \% \mathrm{CI}, 1.39$ 2.48) and were significantly more likely to rate their clinician favorably across all responses in the personal physician communication domain.

Compared with patients whose surveyed visit was their first ever SMA, those who had previously attended an SMA were more likely to report satisfaction in 2008 (78\% vs $62 \%)$, in $2009(79 \%$ vs $70 \%)$, and in 2010 (77\% vs 63\%). Levels of satisfaction among SMA participants remained stable from 2008 to 2010 (Figure 1; P for trend .83).

\section{DISCUSSION}

In this study of SMAs within primary care across a large multispecialty practice from 2008 to 2010, we found that SMA patients reported greater overall satisfaction compared with usual care counterparts. Higher ratings of timely access to care and sensitivity to care needs among SMA patients likely contributed to this outcome, as well as the appeal of an efficient visit (promoted to prospective patients as "90 minutes from start to finish"). Usual care patients, however, consistently rated higher levels of satisfaction with their relationship with their clinician compared with SMA peers. Although prior studies have demonstrated patient acceptance of SMAs in subspecialty clinics, ${ }^{9-12}$ the results of this study suggest that large-scale SMA implementation using an established SMA model within primary care may be associated with increased patient satisfaction compared with usual care.

Of interest is the observation that SMA patients provided lower physician communication ratings and also reported less time with their physician than in a traditional visit. Several possible explanations could account for this finding. First, this study was conducted shortly after the implementation of a new SMA program, so clinicians were relatively inexperienced with conducting SMAs. Second, physicians in the SMA model play a less prominent role, so the fact that we observed a trend toward SMA patients reporting greater satisfaction with the nurse or assistant, a role

\begin{tabular}{|c|c|c|c|c|c|c|}
\hline \multirow[b]{2}{*}{ Characteristic } & \multicolumn{3}{|c|}{ Before Propensity Matching } & \multicolumn{3}{|c|}{ After Propensity Matching } \\
\hline & $\begin{array}{c}\text { Usual } \\
\text { Care, \% } \\
(n=34,619)\end{array}$ & $\begin{array}{l}\text { SMA, \% } \\
(n=981)\end{array}$ & $\begin{array}{c}P \\
\text { Value }\end{array}$ & $\begin{array}{c}\text { Usual } \\
\text { Care, \% } \\
(n=921)\end{array}$ & $\begin{array}{l}\text { SMA, \% } \\
(n=921)\end{array}$ & $\begin{array}{c}P \\
\text { Value }\end{array}$ \\
\hline \multicolumn{7}{|l|}{ Age, y } \\
\hline$<65$ & $22,608(65)$ & $490(50)$ & $<.001$ & $471(51)$ & $454(49)$ & .4 \\
\hline$\geq 65$ & $12,011(35)$ & $491(50)$ & & $450(49)$ & $467(51)$ & \\
\hline \multicolumn{7}{|l|}{ Sex } \\
\hline Male & $12,347(36)$ & $558(57)$ & $<.001$ & $508(55)$ & $526(57)$ & .4 \\
\hline Female & $22,272(64)$ & $423(43)$ & & $413(45)$ & $395(43)$ & \\
\hline \multicolumn{7}{|l|}{ Racelethnicity } \\
\hline $\begin{array}{l}\text { White, } \\
\text { non-Hispanic }\end{array}$ & $27,556(84)$ & $882(91)$ & $<.001$ & $823(89)$ & $835(91)$ & .4 \\
\hline Other & $5,212(16)$ & $91(9)$ & & $98(11)$ & $86(9)$ & \\
\hline \multicolumn{7}{|l|}{ Insurance status } \\
\hline Private & $22,409(65)$ & $527(54)$ & $<.001$ & $514(56)$ & $491(53)$ & .3 \\
\hline Medicare/Medicaid & $12,161(35)$ & $453(46)$ & & $406(44)$ & $430(47)$ & \\
\hline \multicolumn{7}{|l|}{ Health care use } \\
\hline \multicolumn{7}{|c|}{ Internal medicine visits } \\
\hline$\geq 5$ in prior $12 \mathrm{mo}$ & $22,006(64)$ & $769(78)$ & $<.001$ & $728(79)$ & $728(79)$ & 1.0 \\
\hline$\leq 4$ in prior $12 \mathrm{mo}$ & $12,613(36)$ & $212(22)$ & & $193(21)$ & $193(21)$ & \\
\hline \multicolumn{7}{|l|}{ Urgent care visits } \\
\hline$\geq 2$ in prior $12 \mathrm{mo}$ & $15,241(44)$ & $538(55)$ & $<.001$ & $487(53)$ & $503(55)$ & .5 \\
\hline$\leq 1$ in prior $12 \mathrm{mo}$ & $19,378(56)$ & $443(45)$ & & $434(47)$ & $418(45)$ & \\
\hline \multicolumn{7}{|l|}{$\begin{array}{l}\text { Chronic } \\
\text { conditions }\end{array}$} \\
\hline Hypertension & $13,502(39)$ & $606(62)$ & $<.001$ & $573(62)$ & $585(64)$ & .5 \\
\hline $\begin{array}{l}\text { Cardiovascular } \\
\text { disease }\end{array}$ & $3,003(8)$ & $147(15)$ & $<.001$ & $125(14)$ & $144(16)$ & .2 \\
\hline Diabetes & $4,215(12)$ & $248(25)$ & $<.001$ & $206(22)$ & $233(25)$ & .1 \\
\hline Tobacco use & $12,302(42)$ & $409(50)$ & $<.001$ & $407(52)$ & $382(50)$ & .4 \\
\hline \multicolumn{7}{|c|}{ Number of medications } \\
\hline$\geq 6$ & $17,836(52)$ & $620(63)$ & $<.001$ & $573(62)$ & $586(64)$ & .5 \\
\hline$\leq 5$ & $16,783(48)$ & $361(37)$ & & $348(38)$ & $335(36)$ & \\
\hline
\end{tabular}


having greater prominence in this model of care, highlights the SMA model's team-based approach and may explain the relatively lower physician ratings. Third, we found that patients who had experienced 2 or more SMAs were more likely to be satisfied compared with those who had been to only 1 (Table 3 ). In particular, among patients who had prior SMA experience, our

\section{Table 2. Satisfaction With Care for Propensity-Matched Patients in SMAs Relative to Those in Usual Care Visits}

\begin{tabular}{lcc}
\hline Visit Experience Item & $\begin{array}{c}\text { Adjusted OR } \\
(95 \% \mathbf{C l})\end{array}$ & P Value \\
\hline Enhanced access to care & & \\
Ability to get desired appointment & $1.49(1.21-1.92)$ & $<.001$ \\
Convenience of office hours & $1.22(1.02-1.45)$ & .03 \\
Promptness in returning calls & $1.06(0.91-1.81)$ & .44 \\
Wait for laboratory tests & $1.49(1.21-1.92)$ & .03 \\
Coordination of care & & \\
Speed of registration & $0.94(0.73-1.22)$ & .66 \\
Wait for clinician in examination room & $1.13(0.91-1.40)$ & .28 \\
Clinician information from specialist physicians & $0.86(0.73-1.01)$ & .07 \\
Clinician had information to diagnose/treat & $0.85(0.70-1.04)$ & .11 \\
Personal physician communication & & \\
Clinician explanation of problem/condition & $0.60(0.50-0.73)$ & $<.001$ \\
Information clinician gave about medication & $0.64(0.54-0.77)$ & $<.001$ \\
Time clinician spent with patient & $0.52(0.50-1.60)$ & $<.001$ \\
Concern expressed by clinician & $0.58(0.50-0.70)$ & $<.001$ \\
Team-based care & & \\
Friendliness/courtesy of nurse/assistant & $1.27(0.97-1.65)$ & .08 \\
Concern nurse/assistant showed for problem & $1.13(0.96-1.34)$ & .15 \\
Whole-person orientation of care & & \\
Sensitivity to patients' needs & $1.34(1.08-1.65)$ & .01 \\
Concern for patients' privacy & $1.14(0.97-1.35)$ & .12 \\
Patient's confidence in clinician & $1.13(0.91-1.38)$ & .27 \\
Overall impressions & & \\
Overall satisfaction with care provided in visit & $1.26(1.05-1.52)$ & .01 \\
Recommend clinician & $0.93(0.75-1.16)$ & .54 \\
\hline OR & & \\
\hline
\end{tabular}

$\mathrm{OR}=$ odds ratio; $\mathrm{SMA}=$ shared medical appointment.

Note: Odds of rating the item as "very good." Results are propensity score matched to account for differences in variables that are related to SMA participation. See Methods for details.

Table 3. Satisfaction With and Perceptions of the Clinician Among SMA Patients According to Previous Experience

\begin{tabular}{lcc}
\hline & $\begin{array}{c}\text { Adjusted OR } \\
\mathbf{( 9 5 \% ~ C l )}\end{array}$ & P Value \\
\hline Visit Experience Item & $1.86(1.39-2.48)$ & $<.001$ \\
Overall satisfaction with care provided in visit & $1.58(1.17-2.14)$ & .003 \\
Clinician explanation of problem/condition & $1.54(1.16-2.03)$ & .003 \\
Information clinician gave about medication & $1.58(1.17-2.12)$ & .002 \\
Time clinician spent with patient & $1.63(1.19-2.25)$ & .003 \\
Concern expressed by clinician & & \\
\hline OR = odds ratio; SMA = shared medical appointment. & & \\
Note: Odds of rating the item as "very good," comparing patients with prior SMA experi- \\
ence $(n=569)$ with patients in their first SMA ( $n=352)$. \\
\hline
\end{tabular}

findings suggest a more favorable perspective toward the clinician compared with patients attending $1 \mathrm{SMA}$, suggesting a possible warm-up period, during which patients acclimate to the group dynamic and communication style in an SMA. Our observation that SMA patients of white race provided higher care ratings suggests that cultural practices and expectations surrounding communication may frame patients views of group-based care or satisfaction and could play a role in patients' decisions to pursue SMAs as a modality for their health care. Further research should examine patients' satisfaction with their clinician in longitudinal SMA use and explore potential cultural barriers to SMA satisfaction.

We also found that SMA patients perceived more timely access to care, reinforcing the anecdotal experience described by practices adopting SMAs nationally. ${ }^{1,11,25,26}$ For prompt access, primary care departments were uniformly coached to offer the SMA as an alternative to routine care. The results of this intervention confirm that SMAs may be a potential solution among practices experiencing difficulty accommodating patients in a timely fashion. $25,27,28$

Our study confirms and extends prior literature demonstrating that patient satisfaction outcomes are often mixed despite concerted efforts geared toward improving the patient experience. ${ }^{29-32}$ Some studies have shown an association between patient satisfaction and clinician engagement, attentiveness, and responsiveness to patients' needs or expectations. ${ }^{33-37}$ A recent study showed that many clinicians lack awareness regarding the importance of understanding their patients' expectations, highlighting a potential barrier to improving patient satisfaction. ${ }^{35}$ In our study, the fact that SMA patients reported greater sensitivity to their needs aligns with our observation that the SMA group also reported better overall satisfaction compared with usual care peers. This finding, in line with prior literature, suggests that particular elements of the SMA model, such as eliciting each patient's specific agenda for the visit, requesting discretion regarding matters discussed in the group setting, or the supportive role of the behaviorist, may serve to directly engage patients' needs.

A robust patient-clinician relationship is the foundation to effective delivery of primary care, ${ }^{34}$ so sustained use of SMAs will depend on clinicians' ability to engage and nurture the 
Figure 1. Trends in satisfaction with SMA care, 2008-2010, according to previous experience with this model.

First SMA $(n=352) \quad$ Previous SMA experience $(n=569)$

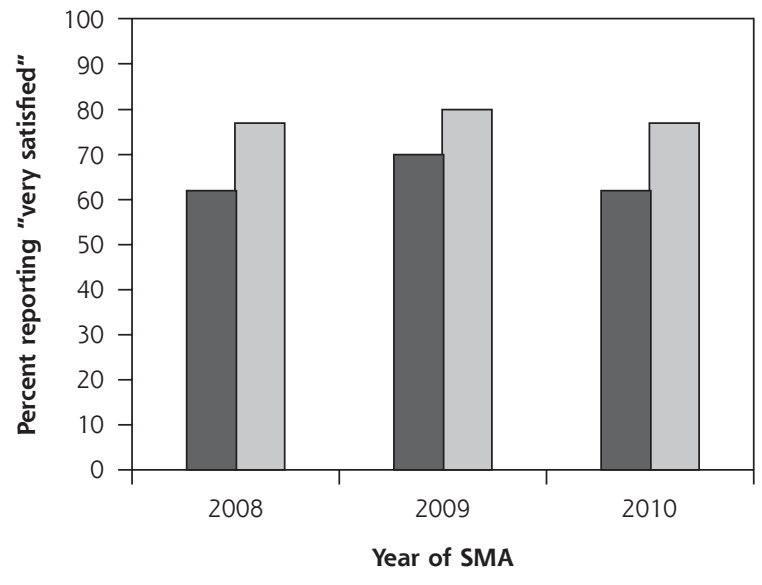

SMA $=$ shared medical appointment

patient in the group setting. To date, medical training programs have structured their patient-doctor curriculum around the traditional patient-doctor encounter consequently, we expected that new SMA clinicians would have varying degrees of comfort and aptitude toward delivering care in a group setting. Physicians who lead SMAs may benefit from training to develop communication skills tailored to group care.

Several limitations should be considered. Although our survey response rates ( $40 \%$ for SMA, 31\% for usual care) are typical of patient experience surveys in nonresearch settings, ${ }^{38,39}$ the possibility of nonresponse bias remains a concern. Institutional review board stipulations did not permit comparison of respondents and nonrespondents to identify systematic differences. Our study sample was primarily white and older, and because this study was not randomized, it is possible that patients self-selected into SMAs after favorable prior experiences with this format or dissatisfaction with usual care, or were preferentially recruited based on manifesting particular chronic conditions. Further investigations using more robust methods, focusing on characteristics of patients who are particularly drawn to SMAs, is an important area requiring future research. Our study faces potential endogenous effects of selection on these characteristics; however, we did the best we could with our data and adjusted for certain experience factors including frequency of usual care or urgent care visits, and used propensity scores, an established method for balancing the observed differences between individuals who self-select to participate in an intervention and those who do not. $21,23,40$
Despite our use of propensity scores, however, the analysis remains limited by unmeasured confounders such as personality traits that may be driving self-selected subgroups of patients toward SMA participation and thereby be responsible, in part, for the observed differences with usual care. Our propensity score conclusions also should be viewed as a conservative approach toward identifying the statistically significant effects since we did not make any adjustments for potential lack of independence between matched pairs. Another important limitation is that our SMAs were implemented within a large, multispecialty network of practices with resources dedicated to SMA development, so results may not be generalizable. In addition, since our study measured satisfaction by patient selfreport, future studies should measure actual wait times to confirm patient perceptions.

Patient-centered, accessible, and timely care is a vital element of quality primary care. Our findings suggest greater overall patient-reported satisfaction, superior appointment access, and enhanced sensitivity to patients' needs with SMAs as compared with the traditional encounter within primary care. In an understaffed primary care system facing growing numbers of eligible patients, ${ }^{41}$ SMA adoption may accommodate a greater number of patients in a timely fashion. ${ }^{25,26}$ Additional research should examine satisfaction with SMAs over time and identify strategies to enhance patientclinician communication within these appointments.

To read or post commentaries in response to this article, see it online at http://www.annfammed.org/content/12/4/324.

Key words: shared medical appointments; patient satisfaction; patient experience; primary care; access to care; patient-centered care; practicebased research

Submitted May 28, 2013; submitted, revised, January 31, 2014; accepted March 10, 2014.

Funding support: Dr Heyworth is supported by HRSA grant T32 HP10251 and by the Department of Veterans Affairs, Veterans Health Administration, Office of Research and Development.

Previous presentation: This work was presented as a poster at the Society of General Internal Medicine's annual conference in Orlando, Florida, May 9-12, 2012.

Acknowledgments: The authors thank Shimon Shaykevich for assistance with coding and programming.

\section{References}

1. Bronson DL, Maxwell RA. Shared medical appointments: increasing patient access without increasing physician hours. Cleve Clin J Med. 2004;71(5):369, 370, 372, 374 passim.

2. Kocher R, Emanuel EJ, DeParle NA. The Affordable Care Act and the future of clinical medicine: the opportunities and challenges. Ann Intern Med. 2010;153(8):536-539. 
3. Burke RE, O'Grady ET. Group visits hold great potential for improving diabetes care and outcomes, but best practices must be developed. Health Aff (Millwood). 2012;31(1):103-109.

4. Clancy DE, Brown SB, Magruder KM, Huang P. Group visits in medically and economically disadvantaged patients with type 2 diabetes and their relationships to clinical outcomes. Top Health Inf Manage. 2003;24(1):8-14.

5. Nutting PA, Crabtree BF, Miller WL, Stange KC, Stewart E, Jaén C. Transforming physician practices to patient-centered medical homes: lessons from the National Demonstration Project. Health Aff (Millwood). 2011;30(3):439-445.

6. Berwick DM. A user's manual for the IOM's 'Quality Chasm' report. Health Aff (Millwood). 2002;21(3):80-90.

7. Berwick DM, Nolan TW, Whittington J. The triple aim: care, health, and cost. Health Aff (Millwood). 2008;27(3):759-769.

8. Kowalczyk L. The doctor will see all of you now. The Boston Globe. Nov 20, 2008.

9. Lorentz PA, Swain JM, Gall MM, Collazo-Clavell ML. Combined group and individual model for postbariatric surgery follow-up care. Surg Obes Relat Dis. 2012;8(2):220-224.

10. Fletcher SG, Clark SJ, Overstreet DL, Steers WD. An improved approach to followup care for the urological patient: drop-in group medical appointments. J Urol. 2006;176(3):1122, 1126; discussion 1126.

11. Bartley KB, Haney R. Shared medical appointments: improving access, outcomes, and satisfaction for patients with chronic cardiac diseases. J Cardiovasc Nurs. 2010;25(1):13-19.

12. Yehle KS, Sands LP, Rhynders PA, Newton GD. The effect of shared medical visits on knowledge and self-care in patients with heart failure: a pilot study. Heart Lung. 2009;38(1):25-33.

13. Scott JC, Conner DA, Venohr I, et al. Effectiveness of a group outpatient visit model for chronically ill older health maintenance organization members: a 2-year randomized trial of the Cooperative Health Care Clinic. J Am Geriatr Soc. 2004;52(9):1463-1470.

14. Beck $A$, Scott J, Williams $P$, et al. A randomized trial of group outpatient visits for chronically ill older HMO members: the Cooperative Health Care Clinic. J Am Geriatr Soc. 1997;45(5):543-549.

15. Clancy DE, Huang P, Okonofua E, Yeager D, Magruder KM. Group visits: promoting adherence to diabetes guidelines. J Gen Intern Med. 2007;22(5):620-624.

16. Edelman D, Fredrickson SK, Melnyk SD, et al. Medical clinics versus usual care for patients with both diabetes and hypertension: a randomized trial. Ann Intern Med. 2010;152(11):689-696.

17. Clancy DE, Dismuke CE, Magruder KM, Simpson KN, Bradford D. Do diabetes group visits lead to lower medical care charges? Am J Manag Care. 2008;14(1):39-44.

18. National Committee for Quality Assurance. NCQA's new distinction in patient experience reporting. http://www.ncqa.org/ PublicationsProducts/OtherProducts/PatientExperienceReporting. aspx. Accessed May 24, 2013.

19. Massachusetts health quality partners. http://www.mhqp.org. 2012. Accessed Nov 5, 2012.

20. American Academy of Family Physicians (AAFP) et al. Joint principles of the patient-centered medical home. American College of Physicians. http://www.acponline.org/running_practice/delivery_ and_payment_models/pcmh/demonstrations/jointprinc_05_17.pdf. 2007. Accessed Oct 17, 2012.

21. Joffe MM, Rosenbaum PR. Invited commentary: propensity scores. Am J Epidemiol. 1999;150(4):327-333.
22. Rosenbaum PR, Rubin DB. Constructing a control group using multivariate matched sampling methods that incorporate the propensity score. Am Stat. 1985;39(1):33-38.

23. Rosenbaum R, Rubin D. The central role of the propensity score in observational studies for causal effects. Biometrika Trust. 1983;70(1):40-55.

24. Zeger SL, Liang KY, Albert PS. Models for longitudinal data: a generalized estimating equation approach. Biometrics. 1988;44(4):1049-1060.

25. Noffsinger EB. The physicals shared medical appointments: a revolutionary access solution. Running Group Visits in Your Practice. New York, NY: Springer-Verlag; 2009.

26. Noffsinger EB. Benefits of drop-in group medical appointments (DIGMAs) to physicians and patients. Group Pract J. 1999;48(3): 21-28.

27. Druss BG, Marcus SC, Olfson M, Tanielian T, Pincus HA. Trends in care by nonphysician clinicians in the United States. N Engl J Med. 2003;348(2):130-137.

28. Naylor MD, Kurtzman ET. The role of nurse practitioners in reinventing primary care. Health Aff (Millwood). 2010;29(5):893-899.

29. Luxford K, Safran DG, Delbanco T. Promoting patient-centered care: a qualitative study of facilitators and barriers in healthcare organizations with a reputation for improving the patient experience. Int J Qual Health Care. 2011;23(5):510-515.

30. Groene O, Klazinga N, Walshe K, Cucic C, Shaw CD, Suñol R. Learning from MARQuls: future direction of quality and safety in hospital care in the European Union. Qual Saf Health Care. 2009;18 (Suppl 1):i69-i74.

31. Wensing M, Vingerhoets $E$, Grol R. Feedback based on patient evaluations: a tool for quality improvement? Patient Educ Couns. 2003;51(2):149-153.

32. Jha AK, Orav EJ, Zheng J, Epstein AM. Patients' perception of hospital care in the United States. N Engl J Med. 2008;359(18):1921-1931.

33. Hospital pulse report. Press Ganey Associates, Inc. http://www. pressganey.com/researchresources/hospitals/pulseReports.aspx. 2011. Accessed Oct 17, 2012.

34. Gerteis M, Edgman-Levitan S, Daley J, Delbanco T. Through the Patient's Eyes: Understanding and Promoting Patient-centered Care. San Francisco, CA: Jossey-Bass; 2002.

35. Rozenblum R, Lisby M, Hockey PM, et al. Uncovering the blind spot of patient satisfaction: an international survey. BMJ Qual Saf. 2011;20(11):959-965.

36. Schoenfelder T, Klewer J, Kugler J. Determinants of patient satisfaction: a study among 39 hospitals in an in-patient setting in Germany. Int J Qual Health Care. 2011;23(5):503-509.

37. Frampton S, Guastello S, Brady C, et al. Patient-centered Care: Improvement Guide. Derby, Connecticut: Planetree; 2008.

38. Abramson J. Survey Methods in Community Medicine. 4th ed. Edinburgh, Scotland: Churchill Livingstone; 1990.

39. Edwards P, Roberts I, Clarke $M$, et al. Increasing response rates to postal questionnaires: systematic review. BMJ. 2002;324(7347):1183.

40. Rosenbaum PR, Rubin DB. Reducing bias in observational studies using subclassification on the propensity score. J Am Stat Assoc. 1984;79(387):516-524.

41. Bodenheimer T, Pham HH. Primary care: current problems and proposed solutions. Health Aff (Millwood). 2010;29(5):799-805. 